\title{
The Use of Information Technologies in Primary School Students Teaching: the Experience of Japan
}

\author{
Nataliia Bakhmat, Tetiana Fedirchyk
}

The article considers the problem of using information technology in teaching primary school students in Japan. It was studied the experience of Japan, where age is not an obstacle to the study new technologies in educational institutions. The Japanese are convinced that the basics of robotics should be learned by children at an early age. The study of IT as a discipline is aimed at instilling an interest in mathematics, science and technology. Children make the first attempts to create robots in elementary school. The need for the implementation of the studied areas and ways of teaching IT in Japan in the primary school of Ukraine is determined, the recommendations of the training and continuous support of teachers are formulated.

Keywords: reforming, personal computer, robotic technologies, electronic educational resources.

\section{Introduction}

Integration of Ukraine into the world community, formation and strengthening of interrelations of pedagogical and scientific communities of different countries naturally actualizes the need for research and analytical review of the state, tendencies and prospects of pedagogical education development of different countries in order to clarify the most effective areas of development of primary school pedagogy in Ukraine with the prospect of using and adapting the results to the conditions of our country.

Education reform in Ukraine is carried out in the conditions of dynamic informatization of society. The level of informatization of education can be considered one of the main indicators of the development of countries. It should be noted that the processes of informatization of society and education are interconnected and interdependent - the level of modern education must correspond to the existing social order. For some time now, information technology (IT) has become a powerful catalyst and indicator of education reform, including primary school. 
In Ukraine, there is a certain separation of the needs for the IT use and the practical reality in primary school. Nowadays, IT in NUS assumes a new role of a teacher, development of new pedagogical methods and new approaches in his professional activity. The success of IT implementation in primary school depends on the ability of primary school teachers to integrate IT into the learning environment.

Ways of IT introduction in educational process, features of using personal computer during studies are outlined in works of O. Kosenchuk N. \& Bakhmat (2019), V. Bykov, \& M. Shihkina( 2014), V. Bykov \& O. Spirin (2017), A. Gurzhiy \& V. Lapinsky (2013), L. Kartashova (2017), S. Lytvynova (2014) and others.

However, the pace of IT development is ahead of scientific advances in this field. The contradiction between IT potential and the level of IT using in the educational process of primary school in Ukraine requires research intensification in this area, finding answers in foreign experience, including the experience of Japan.

The purpose of the study is to analyze the experience and justify the use of information technology in the education of primary school students in Japan.

Objectives of the study: to study the experience of Japan in the use of information technology in teaching primary school students, to consider the problem of studying IT as an incentive to study mathematics, science and technology, to identify recommendations for training and continuous support of teachers.

\section{Material and Methods}

To solve the tasks, the following research methods were used in the work: theoretical - the study of domestic and foreign psychological and pedagogical, methodological, didactic literature on the problem of research; analysis and generalization of experience in implementing IT in the educational process of primary school, pedagogical experience in using IT; analysis of software and didactic opportunities of IT used in the educational process of primary school.

\section{Discussion}

The innovative ways of using information technology in the education of primary school students in Japan, the existence of the outlined contradiction, the objective need to study the conditions of IT use in primary school led to the choice of the research topic (Pronnikov, V. \& Ladanov, 1991). 
The processes of primary education modernization, determined by innovative changes in the new Ukrainian school (NUS), are aimed at the thorough development of each student's personality and the continuity of teacher training and education. The normative and legal basis of the outlined are «Strategies of innovative development of Ukraine for 2010-2020 in the context of globalization challenges» (2010), «National strategy for the development of education in Ukraine until 2021» (2013), sectoral «Concepts of continuing pedagogical education» (2013), The Concept of the New Ukrainian School and the Millennium Development Goals, adopted at the United Nations Summit.

All outlined documents characterize the leading direction - the introduction of innovative concepts, which are aimed at ensuring the diverse educational requirements of each individual.

\section{Results}

Japanese culture considers the school as a spiritual community and a fundamental foundation for the formation of personality: teachers have the greatest responsibility for the moral education and development of each and for instilling basic Japanese values, attitudes and skills of students at all levels of education.

Education in primary school in Japan is considered one of the important events in the life of every person - it is considered a fundamental factor in forming a positive attitude to continuity of education. After graduating from a pedagogical school, the PS teacher must be prepared to work with a class that can have about thirty students. The teacher must be able not only to perform educational functions, but also be ready to perform training functions - which necessarily involves the use of IT to support the study of disciplines, monitoring student performance, etc.

In Japan, children attend primary school for six years. In primary school they study native language, arithmetic, natural sciences; there are also lessons in morality, calligraphy (sodo), music, drawing, ecology, various sports, as well as a course in seikatsu («On Life»).

The curriculum includes the following subjects: social studies, arithmetic, science, environmental research, arts and crafts, physical education and housekeeping. Requirements for the preparation of students also include extracurricular activities, a course of moral education and integrated learning, which can cover a wide range of topics (international understanding, environment, volunteering, etc.). However, reading and writing are probably the most important parts of the primary school curriculum (Average Salaries for Primary School Teachers, 2020; Education 
in Japan, 2020; Elementary School Teacher, 2020; Japan School starting age, primary school (years, source: UNESCO), 2020).

In primary and lower secondary schools, a five-level grading scale is used: S - very good, A - good, B - satisfactory, C - poor, D - very poor.

After graduating from high school, sixth-graders go to junior high school, where they study for another three years. They study native and foreign languages, mathematics, history, geography and other subjects. Much attention is paid to aesthetic education: music, singing, drawing.

The obligatory school program includes excursions to historical places and reserves, during the years of schooling Japanese children visit different parts of the country, getting acquainted with its nature and sights.

Sports are encouraged in every possible way, hygiene and physical education classes are held regularly. As a rule, students are fond of volleyball, basketball, tennis, football and hockey, swimming and other sports. Every year, in the spring and summer, national baseball tournaments are held among schools that are monitored throughout the country.

Historically, support for the installation of computer systems in Japanese schools began in 1985, when the National Council for Educational Reform issued a proposal to «Expand the general education system for the transition to the information society.» At the same time, funding was provided for the purchase of equipment. Initially, the emphasis was on ensuring that PCs were introduced in higher education. However, even at this level, the focus was on the study of PCs themselves, rather than their use to study other subjects. For a long time, an element of this approach to PCs remained in the classroom, but the situation is gradually changing and PCs have been integrated into the educational process of primary school (Computer Use in Japanese Schools: Moving Away from BASIC, 2020).

However, their use in the curriculum was still limited to higher education institutions and, in part, to junior secondary schools. At the level of the primary school the course «Fundamentals of Information Technology» remained selective. Only in high schools the PCs were used in the teaching of subjects such as mathematics or science.

Regarding the spread of the PC use in primary schools in Japan, in general, we can trace a pattern that persisted in both classrooms and office environment: the process was slow, and only in the 90's there was a real impetus to increase the number of PCs and PC viewing, primarily as a way or teaching tool in schools, rather than as learning objectives.

The level of PC penetration looked very different, depending on the level of education. Statistics from the Ministry of Education (as of March 1994) showed that almost all $(99.9 \%)$ public higher education institutions now had some computer equipment. The corresponding percentage was 
$98.4 \%$ for primary and secondary schools, but only $66.1 \%$ for primary schools. These figures, however, include PCs for faculty and administrative use or there may be the only PC that serves the entire school - that is, they do not necessarily indicate the widespread use of PCs by students. In the 1990s, the main task of the Ministry of Education was to provide more PCs to primary schools. In the future, the situation improved rather quickly: at that time, the Japanese government announced a direction to increase the number of PCs at all levels of education by 1999 (Primary and Secondary Education. Japan Table of Contents, 2020).

As the use of PCs in the curriculum was almost non-existent at the initial level, and there was an optional or limited course at the intermediate level, the extension of this process was initiated by teachers. The Ministry of Education recognized that it was necessary to move away from students simply accumulating information, that it was necessary to look for ways to develop their real practical skills in terms of creativity and critical abilities. The Japanese government saw that computers could be the main tool in this process. To this aim the number of PCs available in public schools was almost doubled to 900,000 by 1999 .

The realizing that society is expected to change dramatically in the coming years due to globalization and the need to survive in a constantly changing environment, has led to the need to develop everyone's ability to select the necessary information and make decisions using it in Japan. To do this, you need to learn to use media and IT tools. The Japanese government has focused on the next stage of development of IT education, which would use the results obtained by schools that have participated in testing projects on the use of IT, with a view to their implementation in many other schools (Attitudes towards the use of ICT in schools in Japan, 2020).

Already in 2013, the Ministry of Education, Culture, Sports, Science and Technology noted the positive results obtained from the use of IT in education, such as increasing student motivation, improving learning outcomes. A review of various initiatives in schools shows that schools are constantly developing IT know-how and increasingly providing mare complex learning experience in the classroom.

At the same time, there is an increasing number of school teachers who develop and provide clear instructions for students on the use of IT as a tool. They are also successful in helping children to expand and deepen their development through the use of IT. Table 1 shows the conditions of IT training in each school, which were identified on the basis of a survey conducted by the Institute of Education and Science in Bence.

The table shows that in 2013 more IT events were held in schools than ever before. These include: 
1. Effective use of teaching aids: electronic boards, tablets.

2. Perception of more effective teaching methods and improvement of educational materials; forming learning time so that students can think and share thoughts with peers: for example, displaying letters on a whiteboard, students can easily understand the views of their classmates, compared to listening to verbal presentations in front of the class; teachers develop an educational process that consists of a task $\rightarrow$ individual work (thinking separately) $\rightarrow$ work in pairs / groups (exchange of views) $\rightarrow$ exchange of views with the class $\rightarrow$ explanations and summaries.

3. Encouraging deeper, reflective thinking by doing collaborative tasks stimulated by collaborative software: Some schools worked together to ask children to create a single issue in groups using collaborative software. For example, when a group of children is asked to study earthquakes, there are several topics about earthquakes, such as «A: Quakes, B: seismic intensity, C: distribution of earthquakes, D: catastrophes caused by earthquakes.» Then each child in the group takes responsibility for one of these topics and collects relevant data. Eventually, all data collected by team members will be summarized and displayed as a single report. In this way, students can learn to participate voluntarily in group activities by completing common tasks and, at the same time, deepen their own ideas. 
Tab. 1. Educational activities in schools in Japan using IT

\begin{tabular}{|c|c|c|c|c|c|c|c|c|c|c|c|c|c|c|}
\hline & & \multicolumn{6}{|c|}{ Elementary school } & \multicolumn{7}{|c|}{ Junior high school } \\
\hline \multicolumn{2}{|c|}{ Examples of axtwities (in class) } & A & B & C & $D$ & E & $F$ & A & B & C & $D$ & $E$ & $F$ & G \\
\hline \multirow{5}{*}{ Study materials } & $\begin{array}{l}\text { Explanations by enlarging study materials using an } \\
\text { electronic blackboard, etc. }\end{array}$ & - & $\bullet$ & 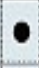 & 0 & 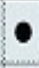 & - & - & 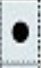 & 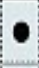 & 0 & 0 & - & $\bullet$ \\
\hline & $\begin{array}{l}\text { Explanations by using dgital materials such as videos } \\
\text { and 3D images }\end{array}$ & & 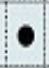 & 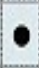 & & & & P & & $\theta$ & 0 & $\bullet$ & & $\bullet$ \\
\hline & Colecting orline materials that soped to chidren & & & 9 & & 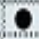 & & 9 & Q & 9 & & & $\theta$ & \\
\hline & $\begin{array}{l}\text { Explanations using projected images of notebooks and } \\
\text { texthooks }\end{array}$ & & & & & ○ & & & 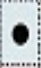 & & & & & \\
\hline & $\begin{array}{l}\text { Using simulation software such as cigital textbooks } \\
\text { (individual work) }\end{array}$ & & & & & & & & & & & & - & \\
\hline Indvidual wark & Summarizing ideas on worksheets & - & 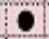 & 0 & 0 & 6 & e & 0 & $\theta$ & & 0 & & 0 & \\
\hline Pait/group work & Working in pars or groups. & & & & & & & & 9 & 9 & 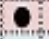 & & e: & \\
\hline Sharing with the class & $\begin{array}{l}\text { Sharing opinions by showing answers on an electronic } \\
\text { blackboard }\end{array}$ & - & - & - & 9 & - & - & - & - & $\bullet$ & 0 & - & - & \\
\hline \multicolumn{15}{|c|}{ Examples of activites (indwidual learning) } \\
\hline \multirow{3}{*}{ Output activities } & $\begin{array}{l}\text { Working together to create materials using collaboration } \\
\text { software }\end{array}$ & $\bullet$ & & 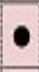 & & & & - & & 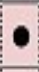 & $\bullet$ & & & \\
\hline & Giving class presentations using presentalion software. & & - & & 9 & & 9. & 9. & & & & & & \\
\hline & $\begin{array}{l}\text { Creating documents using digital materials such as } \\
\text { photos and images }\end{array}$ & C & 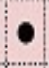 & & 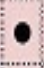 & $\bullet$ & & - & & & & & & \\
\hline Sharng processes & Sharing their thinking process using a digtal pen & & & & & & & & & & 0 & & & \\
\hline Self-reflection & $\begin{array}{l}\text { Improwing their performance by recording and dsplaying } \\
\text { video of their activities (such as gymnastic exercises) }\end{array}$ & & C & & & & & & - & & & & & \\
\hline Dota collection & Colecting necessary information on the Internet & & & & & & & e. & 9 & i & 8 & & & \\
\hline \multirow[t]{2}{*}{$\begin{array}{l}\text { Information } \\
\text { dissemination }\end{array}$} & $\begin{array}{l}\text { Operating the school website (for student-body activities, } \\
\text { etc.) }\end{array}$ & & & & & & & & & & & & 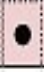 & \\
\hline & Conducting disital drils (indwidual work) & 우․ & & O & 9 & & & (9.1. & & & & (1) & & \\
\hline Dril-and-practice & $\begin{array}{l}\text { Homework using dgital drills and study materials (data } \\
\text { search, reports, classroom video, etc.) }\end{array}$ & & & & & & & & & & $\bullet$ & & - & \\
\hline
\end{tabular}

activities in blue show the use of IT by school teachers

activities in red indicates that children are using the PC or tablet

4. Exchange of thinking with a digital pen: despite the fact that different thought processes lead to the same result, the processes of logical thinking in solving a problem may be different; for example, through group presentations and the use of an electronic board, children can display and explain the process of constructing evidence; Encouraging students to think this way is effective in deepening their understanding of the tasks, as well as in enhancing their thinking, decision-making and skills development.

In its report «Japan: a country of growing robotics», the University of Tokyo said that since the 1970s Japan is at the forefront of industrial robotics. As for the value of exports, Japan is responsible for almost $50 \%$ of the world market share. Demand for robotics from both the public and private sectors in Europe, America, China and other countries outside Japan continues to boost IT development. 
During the years of informatization Japan is famous for its worldclass robotics. In particular, Japan boasts the largest number of industrial robots, such as those designed for car assembly. The country is also the largest exporter of industrial robots.

In Japan, there are many places and ways where children can get in touch with the works and learn about the latest work and development technologies. Many researchers working in enterprises of developing modern robotics technologies are also excited about developing something completely different - educational programs aimed at the development of robotics.

It is known that in Japan there are workshops where children can test their skills in creating robots. Their experience can be so satisfying that after such tests many children choose robotics as their future profession.

Robosquare, located in Fukuoka, on the southwestern main island of Kyushu, is the site of Japan's largest museum of robotics. Students can gain experience in robotics at this museum. Robosquare robots have more than 70 different types of robots: robots that walk on two legs; robots that can sit at home; robots that can conduct quizzes and interact with other users (Robotic Kids. Paving Way for Future Robotics Leaders Japanese, 2020).

A home security robot, which has long been sold in Japan, is able to feel the sounds and temperature changes inside your home, it will call the owner's mobile phone if he finds something unclear.

Robosquare offers many great learning solutions. Visitors can enjoy the performance of a samurai robot dance on stage along with Japanese folk music. Meanwhile, children who want to do more than just observe can also take part in robot creation classes, which provide knowledge of the basics of programming that are necessary to create mobile robots.

In addition to Robosquare, universities and municipalities are launching robotics classes across Japan, giving more and more children the opportunity to gain work experience.

Some children want more than just a game with robots - they want to learn to build a real robot on their own. There is a robotics class especially for children with such ambitious goals. This course launched in Tokyo's socalled «electric town» of Akihabar, is carried out over a four-year period. It began in 2011, when children learned the basics of robotics, such as the properties of metals, building materials and motion mechanics. The course also involves students learning electronic circuits and microcomputers, where the goal is to provide children with all the skills needed to build a robot.

There are also «cram schools» that teach elementary school students robotics in Tokyo and Osaka, where they can begin learning to build robots. 
Using a kit containing special parts developed by Japanese companies and robot experts, they can even build an original robot that differs from the ones shown in the drawings.

Thus, the growth of robotics affects changes in the way of activities in all spheres of life; in turn, this provides Japan's economy with incredibly powerful prospects. Therefore, the Ministry of Education of Japan has recently introduced computer programming (robotics) to the curriculum of all primary schools and it will not be compulsory until 2020 .

That is, recently the Japanese from an early age began to learn the basics of programming. According to the decision of the Ministry of Education, Culture, Sports, Science and Technology, programming will become a compulsory subject in primary school from 2020, a compulsory subject of secondary school from 2021 and a compulsory subject in high school from 2022. Programming improves children's logical thinking and creativity (Japan introduces compulsory programming lessons in primary school , 2020).

In some prefectures of Japan, programming has already been introduced as a compulsory subject in primary school at the initiative of school administrations, community organizations and companies. The first experiments showed a positive result, and now these prefectures will become an example for the national curriculum.

In primary school programming lessons are likely to be added to the science curriculum. This discipline is planned to be studied in the form of a game. For example, some learning materials are developed, where children write programs to control game characters, make up an algorithm of a kind of «building blocks«.

In high school, the Ministry of Education plans to redesign and improve the simple programming examples that are currently taught in labor lessons. Modern high-level programming lessons remain in high school, but over time they will become compulsory.

In some other countries, programming has also become a compulsory subject in the school curriculum. For example, in 2000 he was taught to Israeli students, in 2014 a program of compulsory education in children's programming, starting at 5 years old was introduced in the UK.

It is interesting to note that in order to be more effective, programming lessons in non-English-speaking countries must be accompanied by the compulsory study of English in primary school.

However, nowadays very few primary school $s$ have begun to implement programming and robotics, mainly because teachers are naturally embarrassed that they will have to develop skills that most do not have 
themselves - they are not software engineers. This can be seen as a major obstacle to the development of this process.

It should be noted that the discipline of «Robotics» in primary school does not require high-level theoretical programming teachers. The more teachers are involved in robotics and programming activities, the more confident they are.

The first recommendation for primary school teachers is to avoid «learning» programming - children need to be given creative freedom in what they want to create, without receiving instructions on what to do and how to do it.

The next step for teachers is to find high-quality EERs that allow children to learn through research. It is very important to interest them in all aspects of programming and robotics before they move on to the next stage of learning more formal programming. And, as mentioned above, teachers need to start buying these resources so that they are easy to use in the classroom.

High requirements for the level of knowledge and skills are also confirmed by the fact that at the level of the Ministry of Education requirements for the use of EER have been developed and proposed. One of the popular EERs can be considered a dynamic resource of the Japan Society, which is intended for use by teachers (About Japan. Teacher's resources, 2020) (fig. 1).

This EER provides Japanese educators with an IT space to share, discuss, and develop learning ideas and resources that can be considered a part of the school audience. Basic resource modules:

Essays (essays) - provide a unique perspective on the development of topics, usually wider than they are set out in traditional textbooks and school resources. Providing analysis from experts in the field, essays serve as a starting point for dialogue and further research. Ideally, the essays will «talk to each other» and thus reflect some of the great debate that is relevant to teaching in the classroom. 
Trends and Prospects of the Education System and Educators' Professional ...

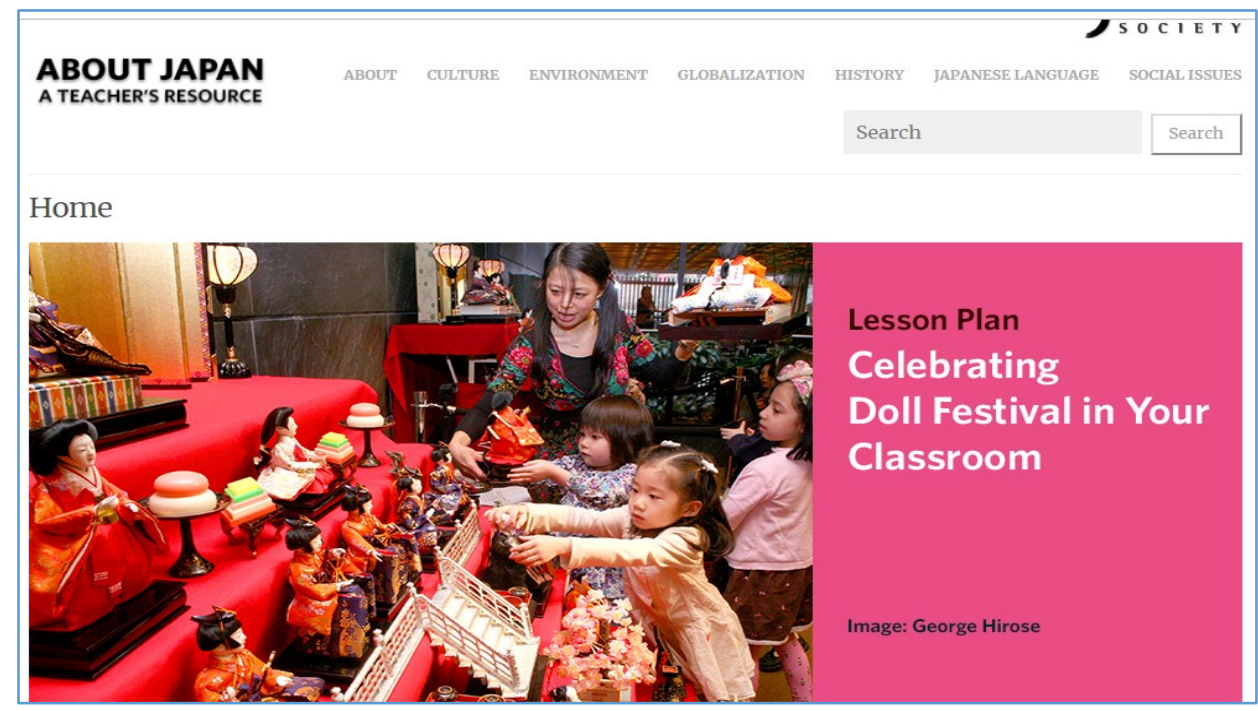

Fig. 1. EER main page «About Japan. Teacher's resources»

Topics - original electronic materials for studying topics that are of particular importance to the school. The developers seek to promote the inclusion of the resource in various educational institutions, developing content on topics that are consistent with the current curriculum through academic disciplines. The editorial staff is constantly updating the content related to these topics.

User profiles - among the members of the on-line registrations, as well as authors and editors who are invited to participate in the work. Visitors must register to use the features of the resource. User profiles can include biographical information and can be used to track and update personal material. This section offers tools for finding people who have similar interests or who work in similar training fields and settings.

Resources (questions) - an open forum for research and information exchange. All participants can ask and answer questions that relate to any aspect of Japanese research or educational practice, including research resources and pedagogy. Questions may include in-depth supporting information. As the developers note, «over time, we hope that these issues will accurately reflect the wide range of interests and learning experiences of the community.

The outlined EERs and lesson plans are developed by the joint efforts of scholars and practicing teachers. They are designed to provide the educational process as contextual tools and effective measures that are necessary in the practice of teachers. 
According to Japanese practices, there are several convenient, highquality resources on the market that can be offered for use: MBot and LEGO Education's WeDo, Boson Kit.

In particular, the Boson Kit allows children to actually build work on the platform, and the appropriate connectors allow them to use a reliable wiring system, in addition, it has two advantages:

- first, its use involves the formation of a sufficient initial level of skills in microprogramming;

- secondly, the acquired knowledge can be useful in science lessons.

What makes it so powerful is that it is equipped with a logic mechanism that combines various inputs and outputs, including a micro-bit, a tiny programmable PC designed for easy and fun learning. By choosing a combination of parts, students are free to learn programming and, in turn, to study the program. Such a resource and the like ones become an important part of children's early education.

One of the best qualities of such resources is that the primary school teacher does not need to be a qualified programmer. After running the program, the teacher can simply provide a fairly broad task and allow them to fantasize about their actions.

For many teachers who use such «teaching» techniques and carry out step-by-step processes, this new way of engaging students can be difficult to adapt. However, it is important that teachers become facilitators, not instructors, allowing children to explore and teach according to their personal imagination.

Teachers need to guide students' activities by understanding that the PC is a tool that allows them to freely demonstrate personal maximum creativity.

Robotics is a new technology for primary school students, so it is important that children at least understand its basics. Teachers need to expand the capabilities of this technology, giving children a special interest in it. In addition to the use robotics for computing, primary school teachers must understand the possibilities to include it in activities in all areas of the curriculum, to attract even students who do not want to learn.

Thus, new changes in the educational process of primary school pose a challenge for teachers - the formation of IT skills, which is not to adhere to the curriculum in accordance with certain standards.

In developing curricula, the Ministry of Education of Japan stated that programming is not the only separate discipline, it should be studied in conjunction with other disciplines, such as mathematics, language, drawing, home economics, ecology and more. 
For example, whether it is a natural disaster, medical treatment or assistance in everyday life, the need for robotics for these and other areas in the future will only increase. By encouraging primary school students to gain as much knowledge about robots as possible, Japan is firmly at the forefront of the industry.

According to Professor Shigeo Hiroshi of the Tokyo Institute of Technology (Information technology and education in the world. LEARNING WORLD, 2020), students at primary school enthusiastically grasp the secrets and mysteries of robotics. He is convinced that the study of this discipline can instill an interest in mathematics, science and technology. After all, children make the first attempts to create robots as a child, then they have a dream to become a good engineer. The scientist-practitioner, who has been working in the field of robotics for 35 years, claims that it is very important to have engineering thinking to create a robot. From an early age, children must learn to properly combine their own intellectual abilities and the ability to feel everything with their own hands. Only in this way future engineers will be able to create robots useful to society.

He gives an example of the developed robots - a snake robot that can provide invaluable assistance to humans in performing difficult and dangerous tasks. Due to its flexibility and ability to explore hard-to-reach places, it is very useful when performing rescue operations. Due to its unique technical capabilities, some engineers call it a "snake charmer». 30 young engineers from different countries worked hard to create it in the laboratory of the great Hiroshi.

Professor Hiroshi is involved in a UN project to develop remotely controlled robots that can detonate mines. Students who want to be like their teacher have a long way to go.

Recently, many Japanese researchers are fighting for the implementation of a communication robot, which is considered a robot that participates in everyday life as a partner, communicates with people as people do, reproducing bodily gestures and expressions, and supports people with their communication tasks.

Research into robotics has led to the development of several practical robots, such as tools for therapy and entertainment, these robots are increasingly expanding the scope of their activities in the daily school life of young Japanese. The Japanese believe that primary schools are promising for the field of operation of work for the purpose of communication. A robot can be a companion with children, although its ability to interact is too limited comparing to human abilities. However, over time, the basic abilities of robots improve, and their role increases accordingly: they are likely to be 
useful for maintaining education and understanding and building friendly relationships among children.

It is believed that in the future, this may help to maintain safety in the classroom, for example, by moderating bullying problems, stopping fights among children and protecting them from violence. That is, communication work for the primary school can be a very effective platform to begin studying how robots are involved in everyday life.

In order to increase their English language skills, next year about 500 Japanese classes will receive English language (AI) robots that work in English. This step was taken by the state, as the country seeks to improve English language skills among children and teachers (Must do better: Japan eyes AI robots in class to boost English? 2020). To that end, the Ministry of Education plans to launch a pilot project worth about 250 million yen (\$ $227,000)$.

AI robots that already exist in the market have different functions, for example, they can check the English pronunciation of each student. AI's work is just one example of testing, and other approaches are planned in the future, such as using tablet applications and conducting online lessons with native speakers. The move is two years ahead of a change in the national curriculum, which will require children aged 10 and over to learn English.

One aspect of IT using in Japanese schools, which differs from schools in countries such as the United States, is the widespread use of complex networks. Depending on the user's request, these networks are used both for two-way communication between students and to give teachers full control over what is happening at each educational terminal. In Japan, many students are in more developed networks than anywhere else.

The desire of the Japanese for disciplined learning has led to the huge emergence of a large number of computer systems (networks) where learning is regulated. It is known that in order to draw the attention of the administration of institutions to networks and build it into something interesting for the students themselves, Apple Japan is conducting an experiment called «Apple Media Kids». This project consists of connecting several PNs across the country, and classes offer the opportunity to jointly study topics such as «lifestyle» or «environment». The schools involved in this pilot project range from Hokkaido in northern Japan to Kyushu in the south. The network system developed by Apple for this purpose is built around an Apple server and offers great flexibility to meet the needs of individual schools. Using the FirstClass client / server package provides a complete graphical network user interface.

Attention should also be paid to the equipment used in the PS - th ere is no reliable data on the market share of the equipment used in schools. 
However, the Japanese argue that the current leader in educational equipment and software can be expected to be NEC (a Japanese corporation, manufacturer of electronic, computer equipment, telecommunications equipment, one of the world's largest telecommunications companies), as well as a leader in the Japanese PC market.

The company offers special training courses for teachers and it has developed PC Educational Software Laboratories for 31 place across Japan, where teachers can come and try the software before deciding to purchase it. In terms of software availability, the NEC catalog lists more than 2,000 special educational use packages.

The recent spread of the popularity of multimedia PCs paves the way for further using of the IT role in the classroom. This is especially necessary in primary schools, where the level of creativity is high, and children are less associated with endless exams, which is typical to Japanese education. The developed Super Yuki NEC educational system allows students to create databases using texts, tables, graphics of all kinds (including moving images) and music. The system offers a wide range of creative tools, as well as a wide range of search functions. Moreover, the additional packages offer other options for creative and educational activities. The Super Yuki interface automatically adjusts to a child's speech skills as soon as they enter information at the login stage, making the system available for six years of primary education.

Despite the NEC dominance in the educational field of the state, other manufacturers are also working to succeed in this area. Apple is a leader in the use of PCs in schools in many countries (its machines are used in $60 \%$ of US schools), and the company is working hard to create a similar situation in Japan. The company pays special attention to facilitating the use of its equipment - not only for students, but also for teachers, whose goal is to quickly implement IT in educational activities as textbooks, rather than the need to devote a lot of time to learn how to use them. Apple offers a large catalog of educational software and, of course, can offer a wide range of packages for learning English.

The experience of Japan shows that coding increases creativity, teaches students to collaborate, work together and communicate in a universal language. Every human-PC interaction is governed by code - programming is everywhere and is the basis for understanding the hyperconnected world. Coding can be considered literacy today, and it helps in acquiring the practical skills needed for the 21st century, such as problem solving, organization and teamwork skills, and the formation of analytical thinking.

In order to provide a quality life for the citizens of our country in the information society and ensure their global competitiveness, it is necessary 
to create interest in programming and strengthening digital competencies. Therefore, the work supports the introduction of programming through various initiatives of Japan. To implement the described areas and ways of teaching IT in Japan in the primary school of Ukraine, it is necessary to implement and comply with the following:

- It is necessary to develop materials and tools for programming lessons that enable effective coding training. Such materials and tools should be easy to use by primary school teachers; they should also be based on real subjects.

- It is advisable to develop an educational coding portal where teachers can easily find and share materials for the lessons.

- The developed tools and materials could also be used for the professional development of PS teachers.

- The developed portal should also become a platform where students could demonstrate personal developments.

However, it should be considered that quality programming training and IT training of students in general correlates with the teacher's training. In order to ensure the effective implementation of the Japanese experience in the educational process of primary education institutions in Ukraine, there is a need to comply with a number of recommendations for the training and continuous support of teachers:

Recommendation 1: Focusing on teachers with low incomes and crisis situations, such as professionals, students and individuals

Recommendation 2: Updating, applying, measuring standards of professional development of teachers in the field of IT.

Recommendation 3: Creating opportunities for professional IT development that will facilitate teacher collaboration.

Recommendation 4: Providing ongoing support to teachers through an appropriate portal designed to address and highlight IT learning and programming issues.

Recommendation 5: Investing in quality pedagogical education.

Recommendation 6: Continuous guidance of the learning process of programming and learning IT at all levels of the education system.

Recommendation 7: Using dedicated IT to provide access to content, professional development and professional teaching communities.

\section{Conclusions}

Some primary and secondary schools have already turned to such IT, in order to deepen the ways of learning English, introducing Englishlanguage robots AI. English classes are currently compulsory for Japanese 
students aged 12 to 15 , but the initial age in 2020 will be reduced to primary school. This indicates the integration of IT with other disciplines.

Japanese education argues that in the study of programming it is important for children to gain knowledge of technologies and processes that are logically embedded in their educational process. After all, no matter what profession they choose in the future: an artist, a doctor or a teacher, robotics will inevitably become part of their future careers.

Although the curriculum change is not mandatory until 2020, teachers from all over Japan should already start selecting ESDs, materials and tips to engage children in a fun and enjoyable experience of all aspects of robotics and programming.

Based on the fact that the use of PC and IT in primary school is not only possible but also necessary, there is a need to study the problem of implementing IT in all activities of the primary school.

The experience of Japan confirms that a powerful phenomenon in the process of wider use of IT in schools is the urgent need to provide appropriate skills to teachers themselves. According to a survey on the use of PCs and IT in education published at the time (September 1994) by the Japanese Association for the Promotion of Educational Technology (JAPET), only one in three teachers was able to use a PC; only one in ten was considered capable of acquiring basic IT skills. Today, there is no teacher who does not have a sufficient level of IT competencies that allow him to use IT in the study of various subjects of primary school.

\section{References}

About Japan. Teacher's resources. Japan Society.

http://aboutjapan.japansociety.org/page/japaneducation home

Attitudes towards the use of ICT in schools in Japan. https://www.childresearch.net/data/school/2014 01.html

Average Salaries for Primary School Teachers: Six Factors that Can Make a Difference. http://education.cu-portland.edu/blog/referencematerial/average-salaries-for-primary-school-teachers/

Bykov, V. \& Shihkina, M. (2014). Emerging Technologies of personnal training for IT indastry in Ukrain. Internecions Conference on interactive collaborative learning, 945-949.

Bykov, V \& Spirin, O. (2017). Problems and taskes of the modern stage of education informatization. Scientific support of education development in Ukraine: current problems of theory and practice. Kiev: National Academy of Pedagogical Sciences, 191-198.

Computer Use in Japanese Schools: Moving Away from BASIC. http://www.japaninc.com/cpj/magazine/issues/1995/may95/05jschl.html 
Education in Japan. http://www.japan-guide.com/e/e2150.html

Elementary School Teacher. http://money.usnews.com/careers/bestjobs/elementary-school-teacher

Information technology and education in the world. LEARNING WORLD. https://ru.euronews.com/2013/06/07/learning-world-looks-at-how-it-isboosting-education-worldwide

Japan introduces compulsory programming lessons in primary school. https://habr.com/post/394533/

Japan School starting age, primary school (years, source: UNESCO. TheGlobalEconomy.com. http://ru.theglobaleconomy.com/Japan/Primary school starting age

Gurzhiy, A. \& Lapinsky, V. (2013). Electronic educational resources as the basis of the modern educational environment of secondary schools. Journal of Information Technologies in Education, 1 (15), 30-37.

Kartashova, L. (2017). Reality of today's school: open electronic textbook. Modern achievements of science and education. XII International Conference, September 17-24.

Kosenchuk, O., Bakhmat, N. (2019). Model of information and communication support of quality management of preschool education. Information technologies and teaching aids, 1, V.69, 246-257.

Lytvynova, S. (2014). The concept and main characteristics of the cloud-based learning environment of secondary school. Information technologies and teaching aids, 5, 26-43.

Must do better: Japan eyes AI robots in class to boost English. https://phys.org/news/2018-08-japan-eyes-ai-robots-class.html

Primary and Secondary Education. Japan Table of Contents. http://countrystudies.us/japan/78.htm

Pronnikov, V. \& Ladanov, I. (1991). Education in Japan. Kyiv: «Knowledge», Ser. 7, Pedagogical, 632, 32.

Robotic Kids. Paving Way for Future Robotics Leaders Japanese. https://webjapan.org/kidsweb/cool/12-08/index.html

The growth of robotics in Japanese schools. https://japantoday.com/category/features/lifestyle/the-growth-of-roboticsin-japanese-schools .

What's been proposed on Computer Science Education in primary school in Japan for 2020. https://medium.com/@ukkaripon/whats-been-proposed-oncomputer-science-education-in-primary-school-in-japan-for-2020$\underline{\mathrm{d} 1543 \mathrm{~cd} 5 \mathrm{e} 461}$ 